\title{
Crash tests for forward-looking flood control in the city of Zürich (Switzerland)
}

\author{
M. Zappa ${ }^{1}$, N. Andres ${ }^{1}$, P. Kienzler ${ }^{2}$, D. Näf-Huber ${ }^{2}$, C. Marti ${ }^{3}$, and M. Oplatka ${ }^{3}$ \\ ${ }^{1}$ Swiss Federal Research Institute WSL, Birmensdorf, Switzerland \\ ${ }^{2}$ Scherrer AG, Reinach, Switzerland \\ ${ }^{3}$ Cantonal Office of Waste, Water, Energy and Air, Zürich, Switzerland \\ Correspondence to: M. Zappa (massimiliano.zappa@wsl.ch)
}

Received: 11 March 2015 - Accepted: 11 March 2015 - Published: 11 June 2015

\begin{abstract}
Floods in the city of Zürich (Switzerland) were already reported in the 13th century. The most severe threat are floods from the Sihl river $\left(336 \mathrm{~km}^{2}\right.$, including also an hydropower reservoir) with peaks exceeding $350 \mathrm{~m}^{3} \mathrm{~s}^{-1}$. An assessment using a rainfall-runoff model has been completed to evaluate extreme flood situations by combining 18 precipitation scenarios with different initial conditions. These scenarios identified deficits for the safety of Zürich. For the improvement of flood management several measures are possible. Crash-tests with 41472 combinations of measures and scenarios have been evaluated. According to the results, the spillway channel option in the downstream reach of the Sihl is a promising structural measure to ensure flood relief for Zürich. Lowering the artificial reservoir lake before the event consistently increases safety also in the upstream part, but causes financial losses in terms of hydroelectricity. The combination of measures can lead to an optimal safety also in case of unfavourable initial conditions. Pending questions concern the costs, political decisions and the environmental sustainability.
\end{abstract}

\section{Introduction}

In Switzerland the awareness of the importance of historical floods is given (e.g. Wetter at al., 2011; Scherrer et al., 2011). The period of measurements in comparison to the knowledge from historical documents is often rather limited. A study published by Schmocker-Fackel and Naef (2010) evaluated the changes in flood frequency in Switzerland since 1850. They found that several regions of Switzerland present increasing flood frequency, when the period 2001-2007 is included in the analysis.

Floods in the small pre-alpine Sihl torrent were already reported in the 13th century (Kienzler et al., 2013). This small river represents the most severe flood threat for the city of Zürich. Damages of several billions Euros including the complete flooding of the central railway station are possible (Addor et al., 2011). Continuous measurements of the Sihl discharge in Zürich started in 1919. The construction of the storage lake "Sihl Lake" in the mid-1930s changed the conditions in the catchment area. From 1910 a flood event with a peak discharge of $470 \mathrm{~m}^{3} \mathrm{~s}^{-1}$ is well documented. Exten- sive research in many archives led to the knowledge of five additional severe floods in 1480, 1562, 1677, 1762 and 1846. Both in May 1999 and in August $2005\left(300 \mathrm{~m}^{3} \mathrm{~s}^{-1}\right.$, highest peak since 1919) the city of Zürich experienced major flood events, with relatively small damage (Hilker et al., 2009).

Local authorities perceived this as an alarm bell. They started a comprehensive program in order to adapt flood management to extreme flooding (e.g. Buchecker et al., 2013). As a first measure in 2008 a state-of-the-art hydrological ensemble prediction system was established (Addor et al., 2011). More recently a series of studies was completed to provide the scientific basis for decision concerning future flood control measures. One of the studies (Kienzler et al., 2013) realized 18 precipitation scenarios (target return periods of 100 and 300 years, Sect. 2.3) that were propagated through the hydrological model PREVAH (Viviroli et al., 2009a, Sect. 2.1). Furthermore a series of pre-assessments identified a set of possible flood management and control measures that could be implemented to cope with extreme situations (Sect. 3). Uncertainty and effects of different initial 


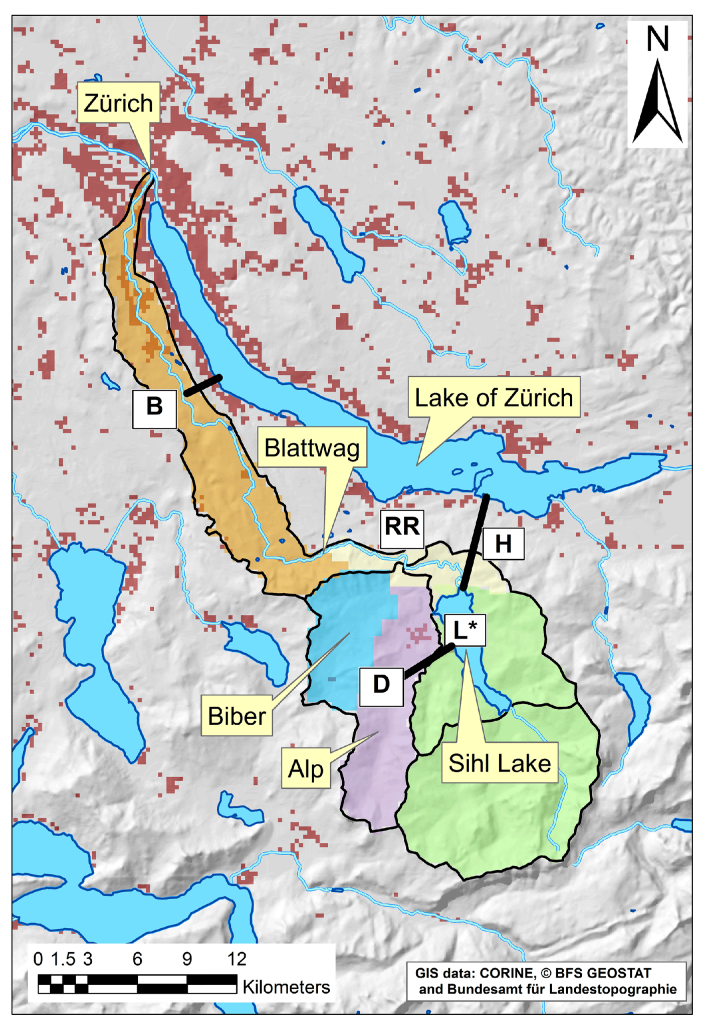

Figure 1. Overview map of the Sihl river and its sub-catchments. The white lables visualize the major flood management options. See further details in the text and in Fig. 3. Red areas represent built-up regions. GIS elements reproduced by kind authorization of "swisstopo" (JA022265), BFS GEOSTAT/BUWAL.

conditions within the target area needed also to be assessed (Sect. 2.2).

Taking example form approaches used in large sample hydrology (Gupta et al., 2014) a "crash-test" with 41472 combinations was evaluated (Sect. 4). Rephrasing Andréassian et al. (2009) such tests allows assessing flood control measures. This is required "to ensure their generality, to diagnose their failures, and to improve them" (Andréassian et al., 2009). In this specific case the options have been assessed by means of hydrological and economic criteria (Sect. 3).

\section{Methods}

\subsection{Study area and hydrological modelling}

The torrential Sihl river basin $\left(336 \mathrm{~km}^{2}\right.$ area) is located south-west of the Lake of Zürich (Fig. 1) and drains the waters from a flash-flood prone alpine area. In 1937 an artificial dam has been completed to collect the water resources from a $155 \mathrm{~km}^{2}$ large headwater region (green areas in Fig. 1). The stored volume in the artificial Sihl Lake is managed for hydropower. Currently up to $34 \mathrm{~m}^{3} \mathrm{~s}^{-1}$ can be diverted to the

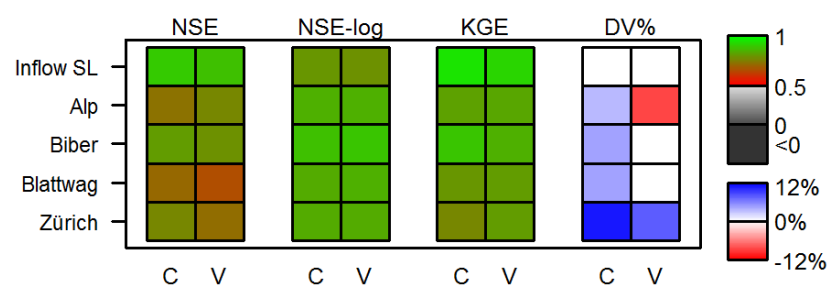

Figure 2. Results of calibration (C) and validation (V) of the modelling chain for different control points within the target area (cf. Fig. 1). SL stays for "Sihl Lake". The measures of agreement are defined in Sect. 2.1.

Lake of Zürich through the pipeline connected to the power generators ("H" in Fig. 1).

Hydrological simulations have been completed using the hydrological model PREVAH (Viviroli et al., 2009a) and a tailored tool that implements the management rules of the Sihl Lake and includes a simplified flood wave translation between the Blattwag and Zürich (Fig. 1). A similar setup is implemented in real-time since 2008 (Addor et al., 2011). Data sources and data processing follows the procedures described in Viviroli et al. (2009a). Model calibration was obtained as described in Viviroli et al. (2009b). Figure 2 indicates the obtained measures of agreement in the calibration and validation periods. Calibration included the years 1997 to 2005 (1999 to 2005 for the inflow to the Sihl Lake), while validation was completed using data for the 2006 to 2011 period. The scores presented are: the Nash-Sutcliffe efficiency (NSE) (Nash and Sutcliffe, 1970), the logarithmic NSE (NSE ${ }_{\text {log }}$ ) (Krause et al., 2005), the Kling-Gupta efficiency (KGE) (Gupta et al., 2009) and the error of the volume in percent (DV \%). Calibration and validation results demonstrated that the adopted model chain is well performing in the target area. $\mathrm{NSE}_{l o g}$ always exceeds 0.8 and KGE always exceeds 0.75 . Concerning NSE reduced skill (still $>0.5$ ) is obtained for the location Blattwag in the validation period. This arises because of the difficulty in correctly capturing the water release from the dam when the lake level rises quickly (see also Addor et al., 2011).

\subsection{Initial conditions}

For the estimation of sensitivity of the Sihl river discharge to initial conditions two different components of the modelling chain have been accounted for: (a) the soil moisture deficit at model initialization, and (b) the initial water level within the Sihl Lake (Fig. 3).

Concerning the soil moisture conditions, three archived initial states of PREVAH stemming from the calibration and validation periods have been isolated by analysing the quantiles of simulated soil moisture availability in the summerhalf year (May to October). The model internal state on 20 May 1999 was selected to represent "wet" initial conditions. The 30 day antecedent precipitation index (API30; 
Table 1. Precipitation scenarios. e01 to e09 represent rainfall events of different duration with a return period of 100 years, while e 10 to e18 represent the return period of 300 years.

\begin{tabular}{llcl}
\hline Scenario & Characteristics & $\begin{array}{c}\text { Duration } \\
{[\mathrm{h}]}\end{array}$ & $\begin{array}{l}\text { Historical } \\
\text { reference event }\end{array}$ \\
\hline e01 \& e10 & Event with two similar peaks & 16 & 1934,1939 \\
e02 \& e11 & Thunderstorm with peak in the early phase & 8 & 2011 \\
e03 \& e12 & Block precipitation (constant intensity) & 24 & $1910,1978,2002$ \\
e04 \& e13 & Block precipitation (constant intensity) & 48 & 1937,2005 \\
e05 \& e14 & Frequent changes in intensities & 30 & Aug 2007, 1999 \\
e06 \& e15 & Event with two peaks and focus downstream & 16 & 1934 \\
e07 \& e16 & Block precipitation with focus upstream & 48 & 1937,2005 \\
e08 \& e17 & Irregular design event & 48 & 2005 \\
e09\&e18 & Design event with peak towards the end and focus upstream & 24 & 2002 \\
\hline
\end{tabular}

Precipitation scenarios «e01» to «e18»
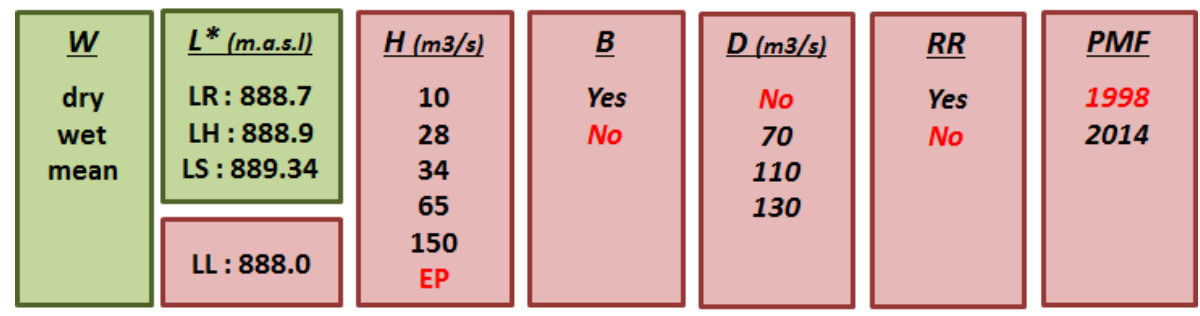

Figure 3. Schematic representation of the tested combinations of precipitation scenarios (blue, Table 1), antecedent hydrological conditions (green) and flood management options (magenta, Sect. 3). The bold red flood management options represent the current situation. Some of the labels are also visualized in Fig. 1.

e.g. Kohler and Lindsay, 1951) for this day was $105 \mathrm{~mm}$, while the saturation deficit of the soil moisture module (Zappa and Gurtz, 2003) was below $2 \mathrm{~mm}$. For "average" initial conditions ("mean") the internal model state on $6 \mathrm{Au}$ gust 2007 has been chosen. API30 was in this case $55 \mathrm{~mm}$ and the moisture deficit was $11 \mathrm{~mm}$. For evaluating "dry" initial conditions the model state on 24 July 2006 has been selected. API30 was about $16 \mathrm{~mm}$ and the model internal state presented a soil moisture deficit of over $30 \mathrm{~mm}$.

The second option to affect the initial state of the model experiment is the definition of different initial levels $\left(\mathrm{L}^{*}\right.$ in Fig. 3) for the Sihl Lake. According to the management rules the lake levels 888.7 ma.s.l. (LR in Fig. 3) and $889.34 \mathrm{~m}$ a.s.l. (LS) play a role for the implementation of the safety rules. LR is the level requiring the beginning of water release to avoid overspill. LS represent the level where overspill starts. Additionally the lake level of 888.9 m a.s.l. (LH) was evaluated. LH represents the typical lake operation level during summer.

\subsection{Precipitation scenarios}

Precipitation scenarios were developed for different return periods (Table 1) and then propagated through the rainfall- runoff model PREVAH for flood hydrograph estimation. The precipitation scenarios rely on observations. The analysis of the 13 largest flood events revealed the critical precipitation characteristics that lead to large floods of the Sihl regarding duration, intensity, temporal course and spatial distribution. E.g. the historical investigation showed that events with bimodal rainfalls, each of them lasting a few days with an interruption of several days, as occurred 1846 or 1999 have an important influence on the initial conditions. Scenarios with a duration of between 8 and $48 \mathrm{~h}$ were developed. The temporal course of the precipitation intensity followed the irregular intensity observed at large events or a constant intensity or a triangle with the peak in the early phase of the event. The spatial distribution was varied following the observed distribution at large events with focus upstream or downstream.

The data base of the extreme value analysis was daily areal precipitation calculated on the basis of rainfall data of 43 gauging stations and of the period 1901-2011 (Isotta et al., 2014). The precipitation sum for different duration and return periods was evaluated by extreme value statistical analysis for the Sihl catchment and sub-catchments (Kienzler et al., 2013). In a first step, yearly maxima of different duration were evaluated. 


\section{Current and possible flood management options}

Currently several technical and infrastructural measures are envisaged in order to improve flood management (see also Buchecker et al., 2013). Figures 1 and 3 list several options for current and future flood management:

- $\left(L^{*}\right)$ Lowering of the level in the Sihl Lake to $888.0 \mathrm{~m}$ a.s.l. (LL). This measure increases the storage volume in the lake. It needs to be triggered by authorities after evaluating the forecasts of the early warning system. A total of about 6.9 million $\mathrm{m}^{3}$ water needs to be released to lower the lake from 888.7 (LR) to 888.0 m a.s.l. (LL).

- (B) Bypassing of water from the Sihl river to the Lake of Zürich. This measure is costly and requires the realization of a spillway gallery diverging peak discharge from the Sihl valley to the Lake of Zürich. Currently it is planned to diverge up to $300 \mathrm{~m}^{3} \mathrm{~s}^{-1}$ as soon as the flood peak heading to Zürich passes the threshold of $170 \mathrm{~m}^{3} \mathrm{~s}^{-1}$.

- (H) Increased diversion by the hydropower pipeline. Currently a maximum of $34 \mathrm{~m}^{3} \mathrm{~s}^{-1}$ can be diverged through the hydropower pipeline in the Lake of Zürich. Most of the time energy production is realized following a weekly plan (EP). If the Lake of Zürich is high, a maximum of $10 \mathrm{~m}^{3} \mathrm{~s}^{-1}$ can be diverged, while generally during floods about $28 \mathrm{~m}^{3} \mathrm{~s}^{-1}$ are turbinated. Future plans envisage to use the hydropower pipeline as spillway gallery with capacities of $65 \mathrm{~m}^{3} \mathrm{~s}^{-1}$ (low cost with limited pumped-storage hydroelectricity) or $150 \mathrm{~m}^{3} \mathrm{~s}^{-1}$ (high investment with intensive pumped-storage hydroelectricity).

- (D) Diversion of the Alp. If the installed hydropower capacity is incremented, additional water needs to be conveyed into the Sihl Lake to justify the financial investment. It is therefore meaningful to plan a further spillway gallery in the Alp river and redirect water to fill the lake (Fig. 1). In these way flood peaks of the Alp can also be controlled and flood protection can be ensured. Currently it is needed to decide which peaks should be guaranteed in the Alp to satisfy environmental matters (sediment budget and environmental flows). Options are listed in Fig. 3.

- (RR) Regulation of water release from the reservoir. The superposition of the peaks of Alp and Biber with the release of water from the Sihl Lake is problematic. A controlled release from the lake to avoid this is planned. This measure should guarantee that peaks of over $300 \mathrm{~m}^{3} \mathrm{~s}^{-1}$ in Blattwag become more seldom. An automatic release procedure relying on measurements needs to be established. We evaluate here the effects of such a procedure with all scenarios.
- (PMF) Change in the safety regulation of the reservoir. In 1998 a safety procedure to avoid the collapse of the dam has been agreed on between the operators, the local administration and the Swiss Federal Office of Energy. This procedure is rather inadequate for the safety of the city of Zürich (Kienzler et al., 2015). Therefore a new regulation has been proposed in 2014. The 2014 version allows for increased storage in the reservoir before opening the gates and guarantees dam safety. A new regulation is a political issue that needs to follow a long legislative procedure prior to implementation.

The adopted basin management tool has been expanded to consider the envisaged flood control mesures. A "crash-test" with 41472 unique combinations of the above described options, precipitation scenarios and initial conditions (Fig. 3) has been completed. Four criteria have been evaluated to discriminate between adequate and inadequate combinations:

- ZH: flood peaks in Zürich need to be below $350 \mathrm{~m}^{3} \mathrm{~s}^{-1}$;

- BW: flood peaks in Blattwag need to be below $300 \mathrm{~m}^{3} \mathrm{~s}^{-1}$;

- VOL_BW: the flood volume above $300 \mathrm{~m}^{3} \mathrm{~s}^{-1}$ in Blattwag need to be minimized;

- Loss_HP: the volume of water released to increase retention capacity in the reservoir should be minimized (release means loss of water for hydroelectricity).

\section{Results}

\subsection{Frequency of critical floods for the city of Zürich}

When the elaborated precipitation scenarios are propagated through the hydrological and routing models in the versions where only the current management options are activated (red in Fig. 3), then basis for extending the flood frequency diagrams are obtained. Figure 4 presents a frequency diagram resulting from the combination of the scenarios with the measurements at the gauging station of the Sihl in Zurich (1938-2011) as well as with the results of the historical analysis (Kienzler et al., 2013). This combination helped to define flood discharges for different recurrence intervals and identify possible magnitude of extreme discharge peaks. Regarding the historical floods, a time period of 530 years could be analysed. The largest floods occurred in 1562, 1677 and 1846. The Sihl showed a (reconstructed) peak of $570 \mathrm{~m}^{3} \mathrm{~s}^{-1}$ on 23 August 1846 and of $470 \mathrm{~m}^{3} \mathrm{~s}^{-1}$ on $14 / 15$ June 1910 . The flood of $22 / 23 \mathrm{Au}-$ gust 2005 with $300 \mathrm{~m}^{3} \mathrm{~s}^{-1}$ was the largest after installation of Lake Sihl in 1937. The damping of Lake Sihl was calculated with PREVAH for the 1910 flood and was estimated for all the large floods before 1937. From Fig. 4 we learn, that most of the considered peak discharges originated when the initial lake level exceeded $888.7 \mathrm{~m}$ a.s.l. (LR). Furthermore 


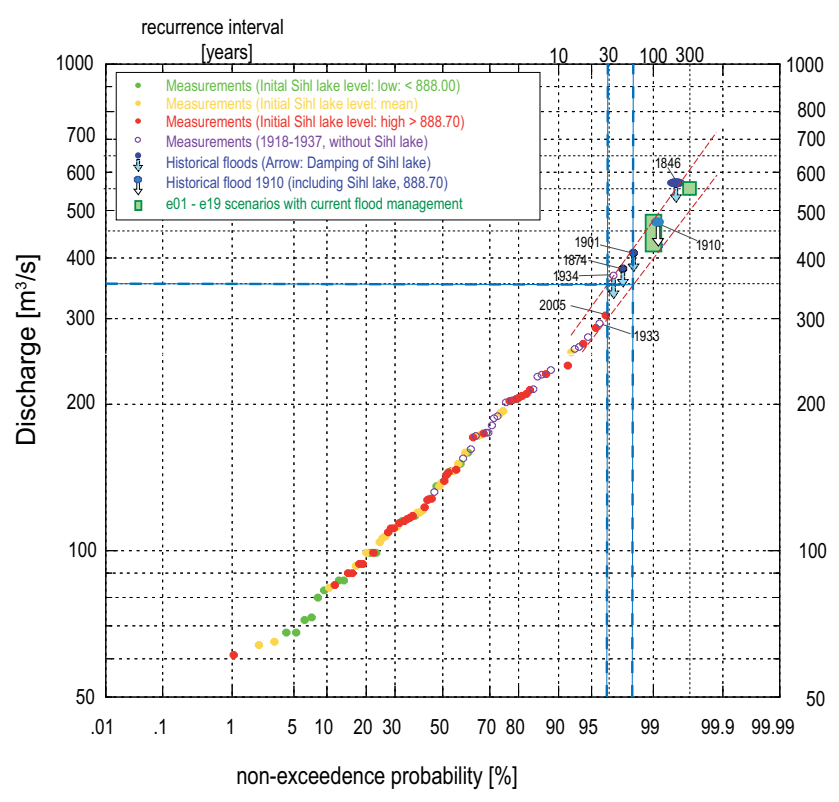

Figure 4. The frequency diagram at the station Sihl-Sihlhölzli in Zurich (Kienzler et al., 2013). Measurements before (1918-1937) and after the construction of the Sihl Lake reservoir (1938-2011) are presented. Different colours signalize the initial level of the Sihl Lake before the event. Historical floods are indicated in blue. For sake of representativeness the light blue arrows show and estimation of the expected damping by the reservoir in the case of historical floods. The green boxes display the range of the calculated peak discharge with PREVAH (Table 1). The red dashed line shows the proposed flood discharges for different recurrence intervals. The blue lines illustrate the range of return period for the $350 \mathrm{~m}^{3} \mathrm{~s}^{-1}$ flood threshold.

the frequency diagram shows that the estimated return period for the threshold of $350 \mathrm{~m}^{3} \mathrm{~s}^{-1}$ is 30 to 65 years. Peak discharge above $350 \mathrm{~m}^{3} \mathrm{~s}^{-1}$ represent a severe threat for the city of Zürich. An analogue evaluation for the Blattwag gauge (Kienzler et al., 2013; not shown) estimated that the return period for the threshold of $300 \mathrm{~m}^{3} \mathrm{~s}^{-1}$ is 45 to 80 years.

\subsection{Evaluation of single options for improved flood management}

Figure 5 indicates how selected subsets of the crash-test combinations fulfilled the four criteria defined in Sect. 3. Each row evaluates the effect of adopting one of the declared relief measures listed in Sect. 3. In the first two main columns of Fig. 5 a visualization of percentage of scenarios (Table 1) exceeding the peak of $350 \mathrm{~m}^{3} \mathrm{~s}^{-1}$ at the Sihl gauge in Zürich (ZH) and the peak of $300 \mathrm{~m}^{3} \mathrm{~s}^{-1}$ in Blattwag (BW) is presented. The third and fourth main columns show the volume of the flood above $300 \mathrm{~m}^{3} \mathrm{~s}^{-1}$ in Blattwag (VOL_BW) and the loss of water volume for hydropower generation (Loss_HP), respectively. The top row ("Orig") shows results obtained with the existing flood management measures (red and bold configuration in Fig. 3). The other rows show the same analysis when one of the planned measures is taken instead: bypass after Blattwag (Byes), regulated release (RRyes), a new dam safety procedure (PMF2014), the diversion of the Alp (D70) and hydropower pipelines with higher capacity (H65 and H150). Results for different initial conditions (dry, mean and wet) and initial level of the Sihl Lake $\left(\mathrm{L}^{*}\right)$ are presented (secondary rows and columns). Here we list a series of findings from Fig. 5:

- The propagation of the scenarios under considerations of the current management measures ("Orig" row) fails to provide flood safety in Zürich and Blattwag in most of the considered options for initial conditions. Only when large soil moisture deficit is considered ("dry" sub-row) and the reservoirs il lowered to $888.0 \mathrm{~m}$ a.s.l. (LL, sub-column) then most of the flood scenarios can be managed.

- The spillway channel option ("Byes" column) guarantees flood relief for the city of Zürich under most conditions. No relief for the upstream part is obtained.

- The regulation of the reservoir release ("RRyes" row) can reduce the number of threatening scenarios in Blattwag and Zürich, when the lake level is at LL or LR.

- A new regulation for management of extreme floods (Kienzler et al., 2015, "PMF2014" row) has positive impact on all criteria evaluated in all sets of initial conditions, including the flood volume in Blattwag (VOL_BW column) and the amount of water loss for hydroelectricity ("Loss_HP" column).

- The diversion of the Alp (D70 column) have very marginal added value, but have positive impact in the cases when the precipitation scenario focus on the Alp and Biber.

- The use of the hydropower pipeline to release water from the reservoir ("H65" and "H150" columns) consistently reduce the flood risk in Zürich and Blattwag and the flood volume in Blattwag. This measure also reduces the losses for hydroelectricity, since considerably less water spills above LS.

Figure 5 demonstrates, that any of the relief measures can guarantee alone safety all along the Sihl in case of initial conditions "mean" and "wet" and in case of initial level of the reservoir at LH and LS.

\subsection{Evaluation of combined options for improved flood management}

Figure 6 shows how combination of flood relief measures impacts the safety of Zürich and Blattwag in case of four 


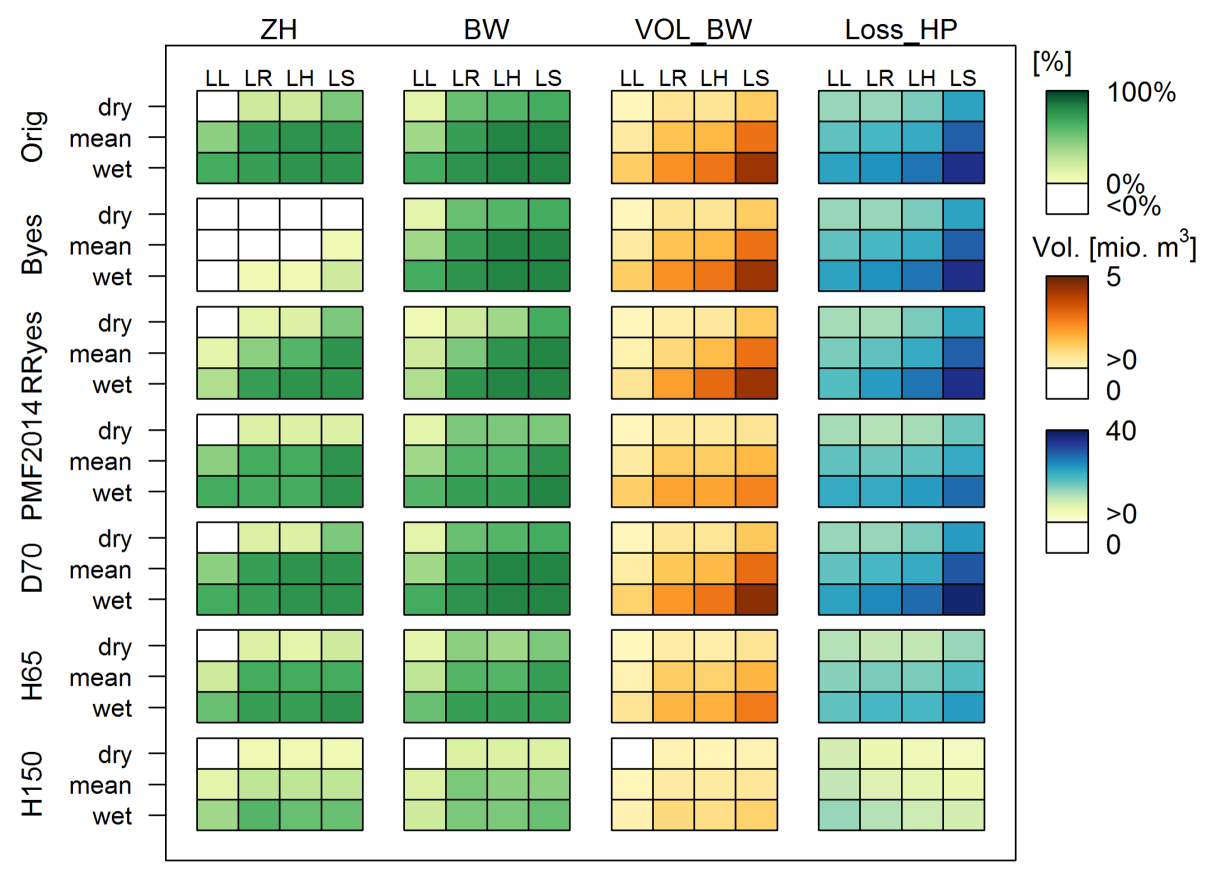

Figure 5. Effect of single management procedures (main rows) as function of different combinations of initial conditions (sub-rows and sub-columns) for different criteria (main columns, cf. last paragraph of Sect. 3). More details on the used notations in Sects. 3 and 4.2 and in Fig. 3.

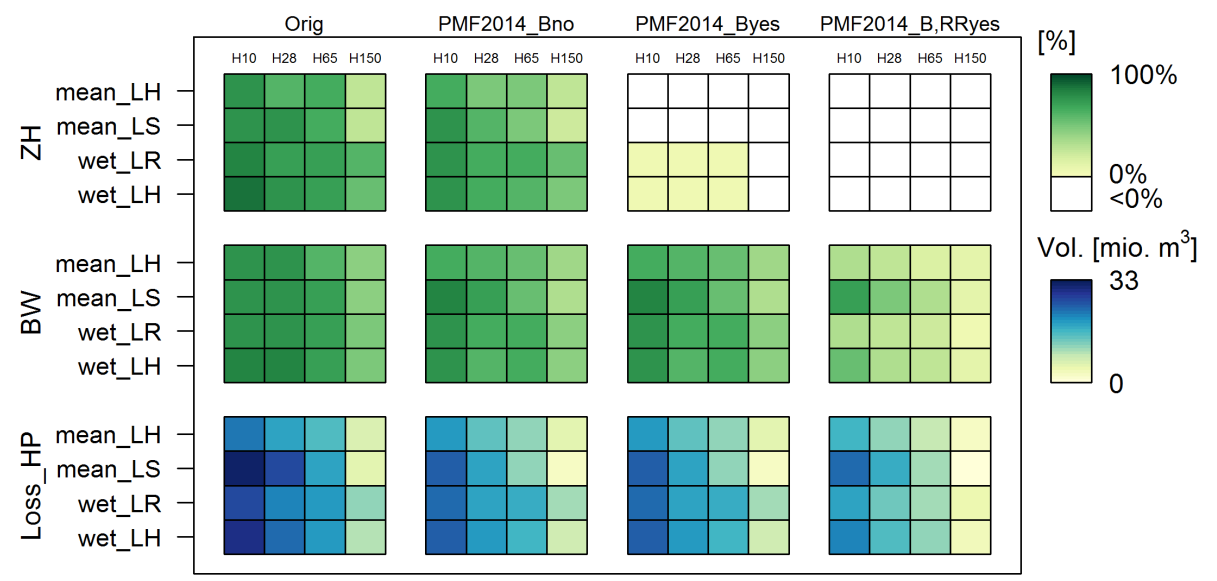

Figure 6. Effect of combined management procedures for selected combinations of initial conditions. Main rows: visualization of percentage of scenarios (Table 1) exceeding the peak of $350 \mathrm{~m}^{3} \mathrm{~s}^{-1}$ at the Sihl gauge in Zürich (ZH), and the peak of $300 \mathrm{~m}^{3} \mathrm{~s}^{-1}$ in Blattwag (BW). More details on the used notations in Sect. 4.3 and in Fig. 3.

unfavourable combinations of soil moisture conditions and level of the reservoir. The main columns indicate which other measures are combined. The main rows indicate here three of the "success criteria" (Sect. 3). The last main row shows the loss for hydropower generation (Loss_HP). The first column (Orig) shows results obtained with the existing flood management measures (bold red configurations in Fig. 3). The second column (PMF2014_Bno) shows results according to the 2014 dam safety procedure. The third column shows the additional effects of bypassing the Sihl after Blattwag (Byes) with the PFM2014 regulation (Sect. 3). The last column also considers regulating the release of the Sihl Lake to damp floods in Blattwag (B, RRyes). The secondary rows present results for different adverse combinations of initial moisture conditions (mean and wet) and level of the Sihl Lake (LH, LS, LR). The secondary columns identify combinations having different quantities of diversion through the hydropower pipeline (H:10 to H:150). The evaluation indicates that:

- The adoption of current management measures ("Orig" column) is inadequate in case of unfavourable initial 
conditions. Flood safety in Zürich and Blattwag can be only improved by diverging large volumes of water through the hydropower pipeline ("H150" sub-column).

- The new regulation for management of extreme floods ("PMF2014_Bno" column) offers moderate relief in all cases and mainly reduces the water loss for hydroelectricity ("Loss_HP" row), since more storage in the reservoir is allowed.

- The addition of the spillway channel option ("PMF2014_Byes" column) to the new regulation option damps all flood scenarios in case of mean moisture conditions as far as the safety of the city is concerned. In case of Blattwag no added value with respect to the "PMF2014_Bno" column is achieved, of course.

- The addition of the regulation of the reservoir release ("PMF2014_B, RRyes" column) is also effective in Blattwag, mostly if the diversion by the hydropower pipeline is high ("H65" or "H150"). In this last case safety in Zürich can be reached in case of all unfavourable initial conditions considered. Also the losses for hydroelectricity can be mitigated.

\section{Conclusions}

This study presented a crash-test for measures planned to improve flood relief in Zürich. The results outline that single measures are less adequate to cope with the multiple threats along the Sihl valley, in Zürich and in the headwater regions in case of unfavourable disposition of initial conditions in the system. The spillway channel option ("B") is the most effective way to reduce flood risk in Zürich, best if combined with a new regulation for the release of water from the artificial lake during floods (PMF2014). Damages in Blattwag can be reduced by adopting a new regulation for the release of water from the reservoir during the event ("RR"), under consideration of the cumulated discharge at the junction between Alp, Biber and the Sihl and in combination with increased release through the hydropower pipeline ("H").

These outcomes are a support for the local authorities, that need to evaluated which relief measure should be realized and/or accelerated and/or skipped. The final decision will account for costs and benefits of each measure. To give an idea the spillway channel ("B") is the most expensive measure and could be realized after all environmental impact assessments (and excluding legal matters) by 2022/2023. The increase of the hydropower pipeline capacity is less expensive but best case evaluations indicate that the realization might take up to 2028. For the establishment of a regulated release procedure ("RR") and for the implementation of a new dam safety procedure ("PMF") limited investments are required ( 2 new discharge stations and electronic equipment). The political matters and legislative procedures are here the time consuming steps, that might be achieved by 2018 . All the presented combinations used tailored versions of the tools that are also implemented in the operational forecasts (Addor et al., 2011). This ensures that any of finally identified measures could be also rapidly adopted in real-time operations.

The methodology presented here might in first-instance appearing to be region-specific. We think that the basic idea of the "Crash-Test" as introduced in hydrology by Andréassian et al. (2009) can be well generalized and applied under several conditions. The basics of the approach are: (a) a system (here the Sihl River) that you model with a specific model (here PREVAH), (b) options (7 in our case) to modify the outcomes (e.g. bypass channel) and test the sensitivity (e.g. antecedent moisture and rainfall scenarios), (c) different configurations (e.g. our Fig. 3) for each options to test the sensitivities, and d) multiple criteria to evaluate the outcomes according to specific needs (e.g. flood peak below a certain threshold at two locations in our case). The presented application demonstrated that flood management options can be tested with such procedure in order to evaluate which measure or combination of measures are most effective for flood control.

In the end we want to remark, that such a "crash-test approach" can generate thousands of implausible, unrealistic or redundant solutions. These can be individuated only if the selected targets are well tailored to obtain clear indications of the problems of the system. If this is guaranteed, than very useful outcomes can emerge and help decision making as in the example we described. By adding economic or ecological criteria one could further discriminate among combinations leading to equally effective flood control.

Acknowledgements. We are indebted to MeteoSwiss and to the Swiss Federal Office for Environment for providing us with all needed meteorological and hydrological data. We thank Hans Schmid and Ueli Kuhlmann for their support. The study is financed by the Office of Waste, Water, Energy and Air of the Canton of Zürich.

\section{References}

Addor, N., Jaun, S., Fundel, F., and Zappa, M.: An operational hydrological ensemble prediction system for the city of Zurich (Switzerland): skill, case studies and scenarios, Hydrol. Earth Syst. Sci., 15, 2327-2347, doi:10.5194/hess-15-23272011, 2011.

Andréassian, V., Perrin, C., Berthet, L., Le Moine, N., Lerat, J., Loumagne, C., Oudin, L., Mathevet, T., Ramos, M.-H., and Valéry, A.: HESS Opinions "Crash tests for a standardized evaluation of hydrological models", Hydrol. Earth Syst. Sci., 13, 1757-1764, doi:10.5194/hess-13-1757-2009, 2009.

Buchecker, M., Salvini, G., Di Baldassarre, G., Semenzin, E., Maidl, E., and Marcomini, A.: The role of risk perception in making flood risk management more effective, Nat. Hazards 
Earth Syst. Sci., 13, 3013-3030, doi:10.5194/nhess-13-30132013, 2013.

Gupta, H. V., Kling, H., Yilmaz, K. K., and Martinez, G. F.: Decomposition of the mean squared error and NSE performance criteria: Implications for improving hydrological modelling, J. Hydrol., 377, 80-91, doi:10.1016/j.jhydrol.2009.08.003, 2009.

Gupta, H. V., Perrin, C., Blöschl, G., Montanari, A., Kumar, R., Clark, M., and Andréassian, V.: Large-sample hydrology: a need to balance depth with breadth, Hydrol. Earth Syst. Sci., 18, 463477, doi:10.5194/hess-18-463-2014, 2014.

Hilker, N., Badoux, A., and Hegg, C.: The Swiss flood and landslide damage database 1972-2007, Nat. Hazards Earth Syst. Sci., 9, 913-925, doi:10.5194/nhess-9-913-2009, 2009.

Isotta, F. A., Frei, C., Weilguni, V., Perčec Tadić, M., Lassègues, P., Rudolf, B., Pavan, V., Cacciamani, C., Antolini, G., Ratto, S. M., Munari, M., Micheletti, S., Bonati, V., Lussana, C., Ronchi, C., Panettieri, E., Marigo, G., and Vertačnik, G.:The climate of daily precipitation in the Alps: development and analysis of a highresolution grid dataset from pan-Alpine rain-gauge data, Int. J. Climatol., 34, 1657-1675, doi:10.1002/joc.3794, 2014.

Kienzler, P., Naef-Huber, D., Scherrer, S., and Frauchiger, R.: Hochwasser-Hydrologie der Sihl, Hochwasserabschätzung unterhalb des Sihlsees bis Zürich, Report 12/159, Scherrer AG, Reinach, 2013.

Kienzler, P., Andres, N., Näf-Huber, D., and Zappa, M.: Herleitung extremer Niederschläge und Hochwasser für das Einzugsgebiet des Sihlsees, Hydrolog. Wasserwirt., 59, 48-58, doi:10.5675/HyWa_2015,2_1, 2015.

Kohler, M. A. and Linsley, R. K.: Predicting the runoff from storm rainfall, US Weather Bureau Research Paper 34, US Weather Bureau, Washington, D.C., 1951.
Krause, P., Boyle, D. P., and Bäse, F.: Comparison of different efficiency criteria for hydrological model assessment, Adv. Geosci., 5, 89-97, doi:10.5194/adgeo-5-89-2005, 2005.

Nash, J. E. and Sutcliffe, J. V.: River flow forecasting through conceptual models, Part I: a discussion of principles, J. Hydrol., 10, 282-290, 1970.

Scherrer, S., Frauchiger, R., Näf, D., and Schelble, G.: Historische Hochwasser: Weshalb der Blick zurück ein Fortschritt bei Hochwasserabschätzungen ist, Wasser Energie Luft, 103, 1, 7-13, 2011.

Schmocker-Fackel, P. and Naef, F.: More frequent flooding? Changes in flood frequency in Switzerland since 1850, J. Hydrol., 381, 1-8, doi:10.1016/j.jhydrol.2009.09.022, 2010.

Viviroli, D., Zappa, M., Gurtz, J., and Weingartner, R.: An introduction to the hydrological modelling system PREVAH and its preand post-processing-tools. Environ. Model. Softw., 24, 12091222, doi:10.1016/j.envsoft.2009.04.001, 2009a.

Viviroli, D., Zappa, M., Schwanbeck, J., Gurtz, J., and Weingartner, R.: Continuous simulation for flood estimation in ungauged mesoscale catchments of Switzerland - Part I: Modelling framework and calibration results, J. Hydrol., 377, 191207, doi:10.1016/j.jhydrol.2009.08.023, 2009b.

Wetter, O., Pfister, C., Weingartner, R., Reist, T., Trösch, J., and Luterbacher, J.: The largest floods in the High Rhine basin since 1268 assessed from documentary and instrumental evidence, Hydrolog. Sci. J., 56, 733-758, doi:10.1080/02626667.2011.583613, 2011.

Zappa, M. and Gurtz, J.: Simulation of soil moisture and evapotranspiration in a soil profile during the 1999 MAP-Riviera Campaign, Hydrol. Earth Syst. Sci., 7, 903-919, doi:10.5194/hess-7903-2003, 2003. 